\title{
The variation of volatile compounds emitted from aromatic orchid (Phalaenopsis bellina) at different timing and flowering stages
}

\author{
Ahmad Asnawi Mus ${ }^{1}$, Jualang Azlan Gansauㄹ, Vijay Subbiah Kumar ${ }^{3}$, Nor Azizun Rusdi ${ }^{1 *}$ \\ ${ }^{1}$ Unit for Orchid Studies, Institute for Tropical Biology and Conservation, Universiti Malaysia Sabah, UMS Road, \\ 88400, Kota Kinabalu, Sabah, Malaysia \\ ${ }^{2}$ Faculty of Science and Natural Resources, Universiti Malaysia Sabah, UMS Road, 88400, Kota Kinabalu, Sabah, \\ Malaysia \\ ${ }^{3}$ Biotechnology Research Institute, Universiti Malaysia Sabah, UMS Road, 88400, Kota Kinabalu, Sabah, Malaysia
}

*Corresponding author: azizun@ums.edu.my

\begin{abstract}
Phalaenopsis bellina, is an orchid widely known for their distinctive fragrance. Of late, fragrant orchids are getting more attention from Orchid breeders for their horticultural market value. Although volatile compounds have been identified in several orchid species, the floral scent emission of $P$. bellina is far from understood. Therefore, this study was carried out to investigate the influence of different timing and floral development stages on the volatile emissions from $P$. bellina flowers using Solid Phase Micro Extraction (SPME) and Gas Chromatography-Mass Spectrometry (GC-MS). The volatile compound was extracted during morning and afternoon sessions from three different floral developmental stages. The volatile compounds emitted from flowers from two different sessions were trapped with SPME fiber for 30 minutes before directly injected into GC-MS for identification. Results showed that approximately 79 volatile compounds were identified, with the terpenoid presented as the major compound class. $P$. bellina had the highest number of volatiles during the morning and full bloom (41), with $29.82 \%$ monoterpene and $23.33 \%$ sesquiterpenes accounted in total. $\alpha$-farnesene (19.56\%) was abundance during morning emission and remains as the highest volatile in afternoon emission (44.08\%), even higher when compared to morning emission. However, a decrease in the volatile compound was observed in afternoon emission, in which only 34 volatile compounds detected. Meanwhile, partial bloom developmental stage revealed linalool as the major terpenoid volatile compounds (25.89\%), with only 20 volatile compounds recorded. On the other hand, no volatile compounds were recorded and profiled from flower bud stage. The establishment of a floral scent study provides a brief overview of the regulation of fragrance in $P$. bellina, which can be continued through gene isolation or fragrance-related enzymes study. This information will provide necessary information on orchid floral scent research that useful in boosting horticultural trade of the scented orchids and their function in pollination ecology study.
\end{abstract}

Keywords: Solid-phase microextraction (SPME); emission; fragrance; Phalaenopsis bellina; Orchids.

\section{Introduction}

In orchids family, also known as Orchidaceae, several families were known to emit their own signature fragrances such as Cypripedioideae, Orchidoideaea, and Epidendroidea (Phillips et al., 2012). Under Epidendroideaea, the tribe Vandeae were composed of many fragrant such as the Phalaenopsis in nature, particularly for Phalaenopsis bellina. $P$. bellina, or also known as "Lundu orchid", or "Norma orchid" is an orchid endemic to the Bornean region (Beaman et al., 2001). The word Bellina is a derivative of Latin etymology, which means beauty/lovely (Martin, 2005). Befitting to its name, it is attractive, with brightly coloured flowers and emits a rather fragrant scent (Christenson and Whitten 1995; Mahmood and Chew 2008). Banks (2003) has described its smell as strong, sweet fragrance with a hint of lemony and citrusy note, and appears most prominent during the morning. Due to its active fragrant feature, $P$. bellina is often used as a donor plant to produce novel Phalaenopsis varieties with new fragrance (Chuang et al., 2017).
The floral fragrance is one of the essential features of the ornamental orchid and can improve the aesthetic value, quality of flower products and their economic merit. Other than that, floral scents are a volatile chemical that plays a role in pollination to boost reproductive success. However in some cases, the floral fragrance itself is the reward to the pollinator (Bera et al., 2017). The role of floral scent is not only limited to attract pollinators but also acts as a repellant to defend themselves against pathogenic microorganisms, insect attacks and herbivory by other organisms (CardosoGustavson et al., 2017).

Cultivating fragrant orchids is a current trend in orchid breeding, with several studies involving orchid volatile compound analysis and synthesis. Phalaenopsis, Oncidium, Ophrys and Neotinea were some of the orchids that were studied, with the minimal research into their volatile aromatic compounds. Then, it is challenging to investigate scent production because floral scents are invisible and variable. To our knowledge, Hsiao et al. (2006) were among the first to explore the volatile composition of $P$. bellina 
through a dynamic headspace sampling system from days five to days ten post-anthesis flower stage. Monoterpenoids, phenylpropanoids, benzenoids and fatty acids derivatives were detected, in which monoterpenoids were accounted as major compound classes in the emission. After 11 years, Chuang et al. (2017) studied the effect of light types and circadian cycle on volatile emission from $P$. bellina. In this study, white light was reported to increase monoterpene linalool, geraniol and eucalyptol emission. In terms of the circadian cycle, emissions of monoterpene were consistent from 10 am to $4 \mathrm{pm}$, and decreases afterward for eight days. Similar patterns were observed when the flower was placed under total darkness, albeit with lower emission intensity when compared to flower placed under white light. Further study of volatile composition in P. bellina by Chuang et al. (2018) revealed the presence of additional terpenoids, which are limonene, neral and ocimene.

Although the study of $P$. bellina volatiles has been conducted, there are no reports on the timing influence and flowering stages in floral scent emission from $P$. bellina flowers. Therefore, in this study, the flowers of $P$. bellina were trapped using Solid Phase Micro Extraction (SPME) during the morning $(9.00 \mathrm{am}-9.30 \mathrm{pm})$ and afternoon (3.00 $\mathrm{pm}-3.30 \mathrm{pm}$ ) and in three flowering stages (flower bud, partial bloom and full bloom). The trapped volatiles were then analyzed using Gas Chromatography-Mass Spectrometry (GC-MS) to profile the volatile diversity between the two emission periods.

\section{Result and discussion}

\section{Effect of different observation period on the Phalaenopsis bellina floral scent emission}

Volatile emission in Phalaenopsis bellina was highly variable during morning and afternoon emission, as profiled in the chromatogram (Figure 1). Approximately, 64 volatile compounds were detected, in which terpenoids contribute significantly towards the aroma of this plant (Table 1). Overall floral scent emission had the largest volatile compounds in the morning (41) and decreased to 34 compounds in the afternoon. $\alpha$-farnesene (19.56\%) were accounted as the highest, followed by 2,6-bis $(1,1$ dimethylethyl)-4-(1-0)oxopropyl)phenol (15.47\%) and 5isopropyl-2,4-imidazolidinedione (9.89\%) that contributed proportion to the scent in the morning. Meanwhile, $\alpha$ farnesene $(44.08 \%)$, linalyl anthranilate $(9.20 \%)$ and linalyl formate $(5.60 \%)$ accounted for the highest compounds in the afternoon. The emission of $\alpha$-farnesene compound was high during morning, and increased in relative abundance during afternoon emission. In terms of compound classes, morning emission shows a total terpenoid abundance of $58.9 \%$, which comprises of monoterpene (24.2\%), sesquiterpene (29.2\%) and triterpene (5.5\%) (Figure 2). Other compound groups were detected as well such as phenols, ketones, fatty acid derivatives, esters, ether, halogen-containing groups, and hydrocarbons, which made up the volatile components. On the other hand, afternoon emission showed the highest abundance of terpenoid $(88.5 \%)$ that encompasses of $82.4 \%$ monoterpene and $6.1 \%$ sesquiterpene. However, the number of volatile fractions detected was reduced, in which only esters, halogencontaining groups, hydrocarbons, phenols, alcohols and different compounds were detected.

Several orchid species also exhibited terpenoid as their main constituents in their volatile compositions. Manzo et al.
(2014) reported the presence of terpenoids as the major constituents of Ophrys sphegodes subsp. Sphegodes and Orphys bertolonii subsp. Benacensis. Similar research was also reported by Yeh et al., (2014) in Phalaenopsis Nobby's Pacific Sunset, in which terpenoids also exist as significant components in its volatiles.

On the contrary, Neotinea tridentate revealed the presence of aldehydes, hydrocarbons and esters as its major volatiles (Manzo et al. 2014). Variation in volatile mixture across orchid species allows for reduced attractiveness to individuals and species, thereby increasing specificity to only selected few pollinator species, such as in bees for pollination of Catasetum species (Milet-Pinheiro and Gerlach 2017). Diurnal bees were known as diurnal pollinators for Phalaenopsis species (Chiu et al., 2017).

A similar trend was also observed in the volatile emission of Phalaenopsis Nobby's Pacific Sunset, in which the volatile emission was most active during the morning (Yeh et al. 2014) for emission of linalool, geraniol, and $\alpha$-farnesene. Chiu et al. (2017) also reported the highest odor emission in the morning from $10 \mathrm{am}$ to $12 \mathrm{pm}$ for Oncidium Rosy Sunset orchid. Interestingly, a similar study conducted by Chuang et al. (2017) revealed otherwise, where emissions of volatiles monoterpene linalool and eucalyptol from $P$. bellina was detected in the afternoon. Yeh et al. (2014) proposed that flower odour was changed at different times to attract different pollinators.

Interestingly, the emission of $\alpha$-farnesene was detected consistently high in both morning and afternoon sessions of full bloom of $P$. belina flower. Several studies have been recorded on the critical functions of $\alpha$-farnesene, especially as a pollinator attraction. Contrary finding, however, $\alpha$ farnesene was reported as a poor pollinator attractant (Hetherington-Rauth and Ramírez 2016). However, the emission of a-farnesene together with other potent scents compounds (linalool and phenylethyl salicylate ) increased the numbers of pollinators such as bees and flies which acting like a behavioral modifier to filter out certain species of pollinators.

Solid Phase Micro Extraction (SPME) was a method that was widely used to trap and capture emitted volatiles for analysis (Shi et al. 2019). Compared to standard headspace extraction that was conducted previously by Hsiao et al. (2006) and Chuang et al., (2017), this method managed to profile a broader range of volatiles, in which several new compounds were managed to identify such as copaene, bergamiol, and linalyl anthranilate. Fan et al. (2019) have indeed agreed to this method since this approach is indeed sensitive and effective in finding scent-related volatiles of Camellia species. On the contrary, (Reis et al. 2004) reported SPME is not effective method to trap volatiles emitted from Stanhopea, Polystachya and Epidendrum orchids, which may suggest SPME performance was varied across species.

\section{Effect of flowering development stages on the Phalaenopsis bellina floral scent emission}

It is difficult to determine which flowering stages produced the most potent scent and to prove the specific volatile composition of the scents (Dudareva and Pichersky, 2000). The chromatogram profile of volatile emission in different flowering development was shown in Figure 3. Emission of volatile compounds from Phalaenopsis bellina has yielded 20 volatiles chemical compounds in partial bloom and increased into 41 volatile chemical compounds in full bloom (Table 2). However, no volatile compounds were detected in flower 
Table 1. Identification of volatile compounds emitted from $P$. bellina flowers at morning and afternoon.

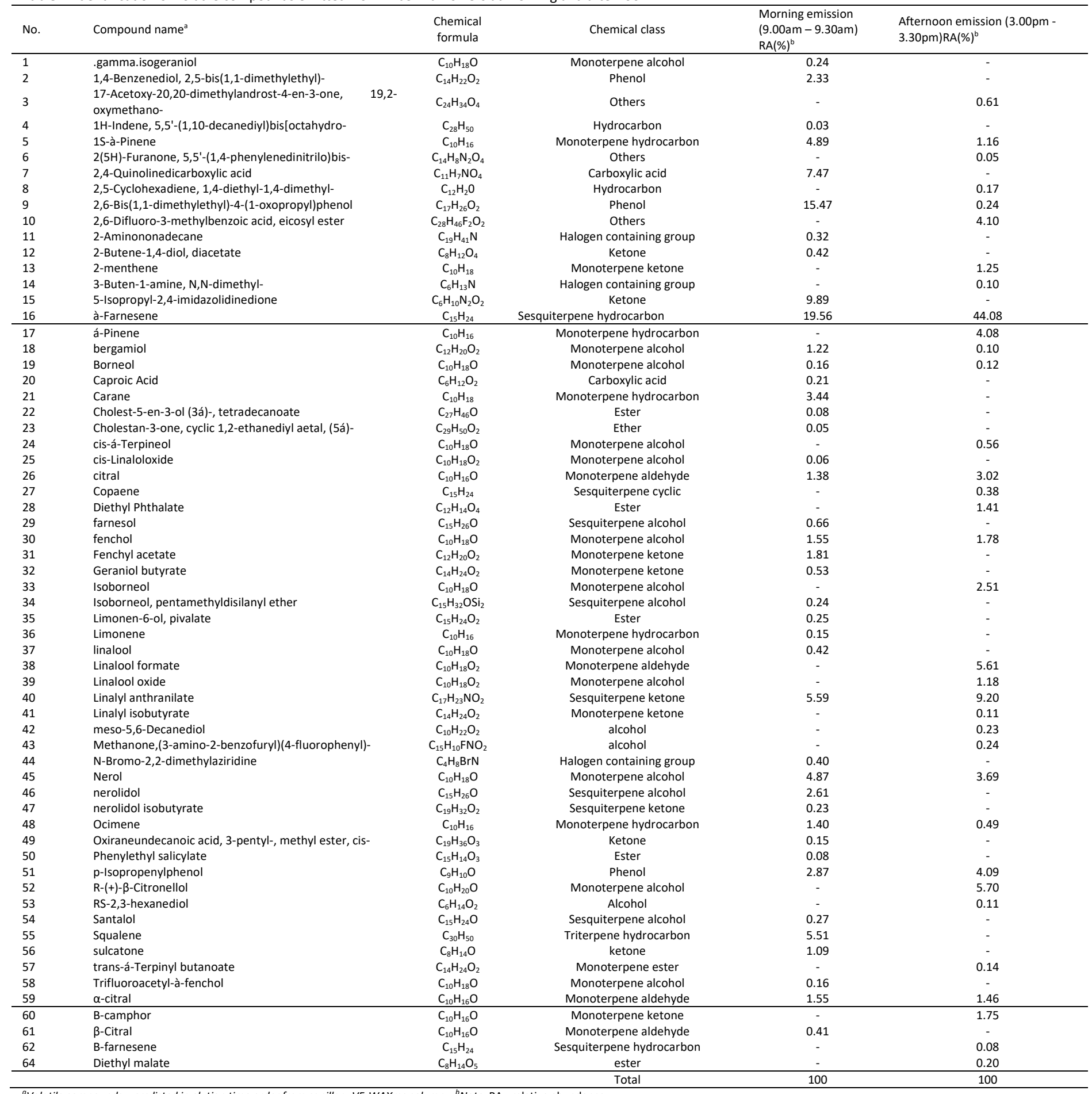

${ }^{a}$ Volatile compounds were listed in elution time order from capillary VF-WAXms column ${ }^{b}$ Note: RA - relative abundance

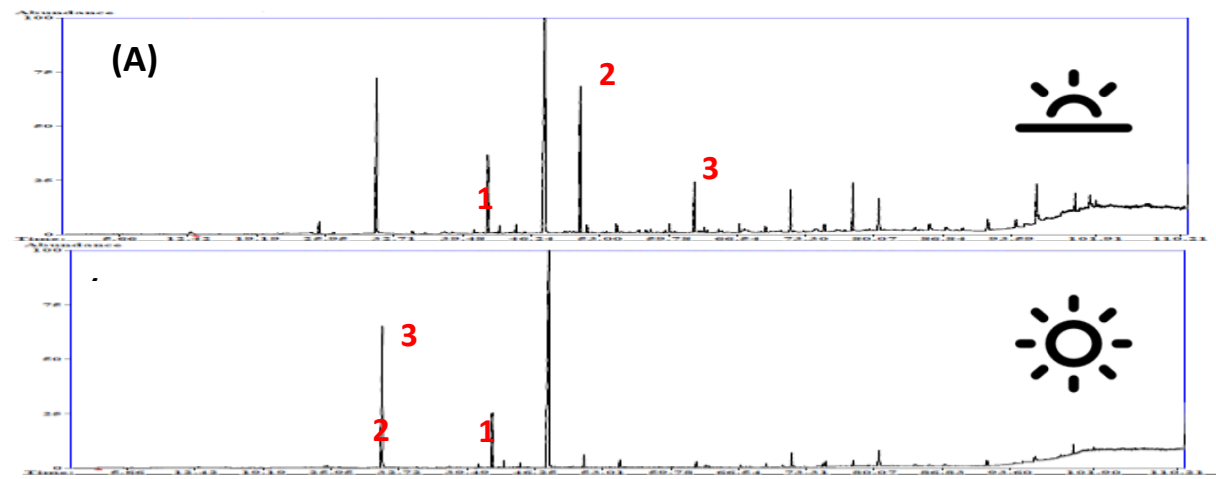

Fig 1. (A) chromatogram of morning emission of $P$. bellina. Top three compounds were labelled in numbers, (1) $\alpha$-farnesene, (2) 2,6-bis(1,1-dimethylethyl)-1-(1oxopropyl)phenol and (3) 5-isopropyl-2,4-imidazolidinedione (B) Chromatogram of afternoon emission of $P$. bellina. Top three compounds were labelled in numbers, (1) $\alpha$-farnesene, (2) linalyl anthranilate, (3) linalyl formate. 
Table 2. Identification of volatile compounds emitted from $P$. bellina fully open flowers at different developmental stages, which were floral bud, partial bloom and full bloom.

\begin{tabular}{|c|c|c|c|c|c|c|}
\hline No. & Compound name & Chemical formula & Chemical class & $\begin{array}{l}\text { Floral bud } \\
\text { RA(\%) }\end{array}$ & $\begin{array}{l}\text { Partial } \\
\text { bloom } \\
\text { RA }(\%)^{\text {b }}\end{array}$ & $\begin{array}{l}\text { Full Bloom } \\
\text { RA(\%) }\end{array}$ \\
\hline 1 & Ocimene & $\mathrm{C}_{10} \mathrm{H}_{16}$ & $\begin{array}{l}\text { Monoterpene } \\
\text { hydrocarbon }\end{array}$ & - & - & 1.40 \\
\hline 2 & $\begin{array}{l}\text { 2-Furanmethanol, 5-ethenyltetrahydro-à,à,5-trimethyl-, } \\
\text { cis- }\end{array}$ & $\mathrm{C}_{10} \mathrm{H}_{18} \mathrm{O}_{2}$ & Furan & - & 0.26 & - \\
\hline 3 & 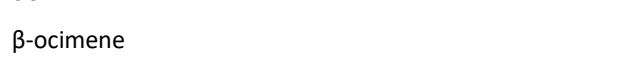 & $\mathrm{C}_{10} \mathrm{H}_{16}$ & $\begin{array}{l}\text { Monoterpene } \\
\text { hydrocarbon }\end{array}$ & - & 0.48 & - \\
\hline 4 & 17-Octadecen-14-yn-1-ol & $\mathrm{C}_{18} \mathrm{H}_{32} \mathrm{O}$ & alcohol & - & 12.75 & - \\
\hline 5 & bergamotene & $\mathrm{C}_{15} \mathrm{H}_{24}$ & $\begin{array}{l}\text { sesquiterpene } \\
\text { hydrocarbon }\end{array}$ & - & 0.08 & - \\
\hline 6 & Tetradecanedioic acid, bis(tert-butyldimethylsilyl) ester & $\mathrm{C}_{26} \mathrm{H}_{54} \mathrm{O}_{4} \mathrm{Si}_{2}$ & Hydrocarbon & - & 0.41 & - \\
\hline 7 & Isophthalic acid, 2,3-dichlorophenyl ethyl ester & $\mathrm{C}_{19} \mathrm{H}_{1} 8 \mathrm{Cl}_{2} \mathrm{O}_{4}$ & aromatic hydrocarbon & - & 4.72 & - \\
\hline 8 & N-Morpholinomethyl-isopropyl-sulfide & $\mathrm{C}_{8} \mathrm{H}_{17} \mathrm{NOS}$ & Halogen containing group & - & 4.75 & - \\
\hline 9 & Tetracosamethyl-cyclododecasiloxane & $\mathrm{C}_{24} \mathrm{H}_{72} \mathrm{O}_{12} \mathrm{Si}_{12}$ & Hydrocarbon & - & 2.12 & - \\
\hline 10 & $\begin{array}{l}\text { 3-Ethoxy-1,1,1,7,7,7-hexamethyl-3,5,5- } \\
\text { tris(trimethylsiloxy)tetrasiloxane }\end{array}$ & $\mathrm{C}_{17} \mathrm{H}_{50} \mathrm{O}_{7} \mathrm{Si}_{7}$ & Hydrocarbon & - & 1.15 & - \\
\hline 11 & $\begin{array}{l}\text { 2-(2',4',4',6',6', 8',8'-Heptamethyltetrasiloxan-2'-yloxy)- } \\
2,4,4,6,6,8,8,10,10-n\end{array}$ & $\mathrm{C}_{16} \mathrm{H}_{48} \mathrm{O}_{10} \mathrm{Si}_{9}$ & Hydrocarbon & - & 3.75 & - \\
\hline 12 & ethylbutenol & $\mathrm{C}_{6} \mathrm{H}_{12} \mathrm{O}$ & alcohol & - & 0.43 & - \\
\hline 13 & 1,3-Dioxane, 4,4-dimethyl- & $\mathrm{C}_{6} \mathrm{H}_{12} \mathrm{O}_{2}$ & ether & - & 2.95 & - \\
\hline 14 & 2,6-Difluoro-3-methylbenzoic acid, nonadecyl ester & $\mathrm{C}_{27} \mathrm{H}_{44} \mathrm{~F}_{2} \mathrm{O}_{2}$ & Ester & - & 3.19 & - \\
\hline 15 & S-Benzoyl(thiohydroxylamine) & $\mathrm{C}_{7} \mathrm{H}_{7} \mathrm{NOS}$ & Halogen containing group & - & 2.42 & - \\
\hline 16 & Phthalic acid, butyl 2-pentyl ester & $\mathrm{C}_{17} \mathrm{H}_{2} 4 \mathrm{O}_{4}$ & ester & - & 0.74 & - \\
\hline 17 & Cyclononasiloxane, octadecamethyl- & $\mathrm{C}_{18} \mathrm{H}_{54} \mathrm{O}_{9} \mathrm{Si}_{9}$ & Hydrocarbon & - & 0.58 & - \\
\hline 18 & cis-Linaloloxide & $\mathrm{C}_{10} \mathrm{H}_{18} \mathrm{O}_{2}$ & Monoterpene alcohol & - & - & 0.06 \\
\hline 19 & Limonene & $\mathrm{C}_{10} \mathrm{H}_{16}$ & $\begin{array}{l}\text { Monoterpene } \\
\text { hydrocarbon }\end{array}$ & - & - & 0.15 \\
\hline 20 & 1S-à-Pinene & $\mathrm{C}_{10} \mathrm{H}_{16}$ & $\begin{array}{l}\text { Monoterpene } \\
\text { hydrocarbon }\end{array}$ & - & - & 4.89 \\
\hline 21 & bergamiol & $\mathrm{C}_{12} \mathrm{H}_{20} \mathrm{O}_{2}$ & Monoterpene alcohol & - & - & 1.22 \\
\hline 22 & borneol & $\mathrm{C}_{10} \mathrm{H}_{18} \mathrm{O}$ & Monoterpene alcohol & - & - & 0.16 \\
\hline 23 & Geraniol butyrate & $\mathrm{C}_{14} \mathrm{H}_{24} \mathrm{O}_{2}$ & Monoterpene ketone & - & - & 0.53 \\
\hline 24 & sulcatone & $\mathrm{C}_{8} \mathrm{H}_{14} \mathrm{O}$ & ketone & - & - & 1.09 \\
\hline 25 & linalyl anthranilate & $\mathrm{C}_{17} \mathrm{H}_{23} \mathrm{NO}_{2}$ & Sesquiterpene ketone & - & 24.01 & 5.59 \\
\hline 26 & linalool & $\mathrm{C}_{10} \mathrm{H}_{18} \mathrm{O}$ & Monoterpene alcohol & - & 32.09 & 0.42 \\
\hline 27 & farnesol & $\mathrm{C}_{15} \mathrm{H}_{26} \mathrm{O}$ & Sesquiterpene alcohol & - & - & 0.66 \\
\hline 28 & nerolidol isobutyrate & $\mathrm{C}_{19} \mathrm{H}_{32} \mathrm{O} 2$ & Sesquiterpene ketone & - & - & 0.23 \\
\hline 29 & nerolidol & $\mathrm{C}_{15} \mathrm{H}_{26} \mathrm{O}$ & Sesquiterpene alcohol & - & - & 2.61 \\
\hline 30 & $\beta$-Citral & $\mathrm{C}_{10} \mathrm{H}_{16} \mathrm{O}$ & Monoterpene aldehyde & - & - & 0.41 \\
\hline 31 & Citral & $\mathrm{C}_{10} \mathrm{H}_{16} \mathrm{O}$ & Monoterpene aldehyde & - & - & 1.38 \\
\hline 32 & $\alpha$-Citral & $\mathrm{C}_{10} \mathrm{H}_{16} \mathrm{O}$ & Monoterpene aldehyde & - & - & 1.55 \\
\hline 33 & à-Farnesene & $\mathrm{C}_{15} \mathrm{H}_{24}$ & Sesquiterpene & - & - & 19.56 \\
\hline 34 & carane & $\mathrm{C}_{10} \mathrm{H}_{18}$ & $\begin{array}{l}\text { Monoterpene } \\
\text { hydrocarbon }\end{array}$ & - & - & 3.44 \\
\hline 35 & gamma.isogeraniol & $\mathrm{C}_{10} \mathrm{H}_{18} \mathrm{O}$ & Monoterpene alcohol & - & - & 0.24 \\
\hline 36 & fenchol & $\mathrm{C}_{10} \mathrm{H}_{18} \mathrm{O}$ & Monoterpene alcohol & - & - & 1.55 \\
\hline 37 & nerol & $\mathrm{C}_{10} \mathrm{H}_{18} \mathrm{O}$ & Monoterpene alcohol & - & - & 4.87 \\
\hline 38 & Fenchyl acetate & $\mathrm{C}_{12} \mathrm{H}_{20} \mathrm{O}_{2}$ & Monoterpene ketone & - & - & 1.81 \\
\hline 39 & Trifluoroacetyl-à-fenchol & $\mathrm{C}_{10} \mathrm{H}_{18} \mathrm{O}$ & Monoterpene alcohol & - & - & 0.16 \\
\hline 40 & 2,6-Bis(1,1-dimethylethyl)-4-(1-oxopropyl)phenol & $\mathrm{C}_{17} \mathrm{H}_{26} \mathrm{O}_{2}$ & Phenol & - & - & 15.47 \\
\hline 41 & 2-Butene-1,4-diol, diacetate & $\mathrm{C}_{8} \mathrm{H}_{12} \mathrm{O}_{4}$ & Ketone & - & - & 0.42 \\
\hline 42 & 1H-Indene, 5,5'-(1,10-decanediyl)bis[octahydro- & $\mathrm{C}_{28} \mathrm{H}_{5} \mathrm{O}$ & Hydrocarbon & - & - & 0.03 \\
\hline 43 & Caproic Acid & $\mathrm{C}_{6} \mathrm{H}_{12} \mathrm{O}_{2}$ & Carboxylic acid & - & - & 0.21 \\
\hline 44 & 5-Isopropyl-2,4-imidazolidinedione & $\mathrm{C}_{6} \mathrm{H}_{10} \mathrm{~N}_{2} \mathrm{O}_{2}$ & Ketone & - & - & 9.89 \\
\hline 45 & Isoborneol, pentamethyldisilanyl ether & $\mathrm{C}_{15} \mathrm{H}_{32} \mathrm{OSi}_{2}$ & Sesquiterpene alcohol & - & - & 0.24 \\
\hline 46 & 1,4-Benzenediol, 2,5-bis(1,1-dimethylethyl)- & $\mathrm{C}_{14} \mathrm{H}_{22} \mathrm{O}_{2}$ & Phenol & - & - & 2.33 \\
\hline 47 & Limonen-6-ol, pivalate & $\mathrm{C}_{15} \mathrm{H}_{24} \mathrm{O}_{2}$ & Ester & - & - & 0.25 \\
\hline 48 & Phenylethyl salicylate & $\mathrm{C}_{15} \mathrm{H}_{14} \mathrm{O}_{3}$ & Ester & - & - & 0.08 \\
\hline 49 & 2-Aminononadecane & $\mathrm{C}_{19} \mathrm{H}_{41} \mathrm{~N}$ & Halogen containing group & - & - & 0.32 \\
\hline 50 & p-Isopropenylphenol & $\mathrm{C}_{9} \mathrm{H}_{10} \mathrm{O}$ & Phenol & - & 3.11 & 2.87 \\
\hline 51 & 2,4-Quinolinedicarboxylic acid & $\mathrm{C}_{11} \mathrm{H}_{7} \mathrm{NO}_{4}$ & Carboxylic acid & - & - & 7.47 \\
\hline 52 & N-Bromo-2,2-dimethylaziridine & $\mathrm{C}_{4} \mathrm{H}_{8} \mathrm{BrN}$ & Halogen containing group & - & - & 0.40 \\
\hline 53 & Cholest-5-en-3-ol (3á)-, tetradecanoate & $\mathrm{C}_{27} \mathrm{H}_{46} \mathrm{O}$ & Ester & - & - & 0.08 \\
\hline 54 & Cholestan-3-one, cyclic 1,2-ethanediyl aetal, (5á)- & $\mathrm{C}_{29} \mathrm{H}_{50} \mathrm{O} 2$ & Ether & - & - & 0.05 \\
\hline 55 & Oxiraneundecanoic acid, 3-pentyl-, methyl ester, cis- & $\mathrm{C}_{19} \mathrm{H}_{36} \mathrm{O}_{3}$ & Ketone & - & - & 0.15 \\
\hline 56 & Squalene & $\mathrm{C}_{30} \mathrm{H}_{5} \mathrm{O}$ & Triterpene hydrocarbon & - & - & 5.51 \\
\hline \multirow[t]{2}{*}{57} & Santalol & $\mathrm{C}_{15} \mathrm{H}_{24} \mathrm{O}$ & Sesquiterpene alcohol & - & - & 0.27 \\
\hline & & & Total & 0.00 & 100.00 & 100.00 \\
\hline
\end{tabular}

${ }^{o}$ Volatile compounds were listed
${ }^{b}$ Note: RA - relative abundance 


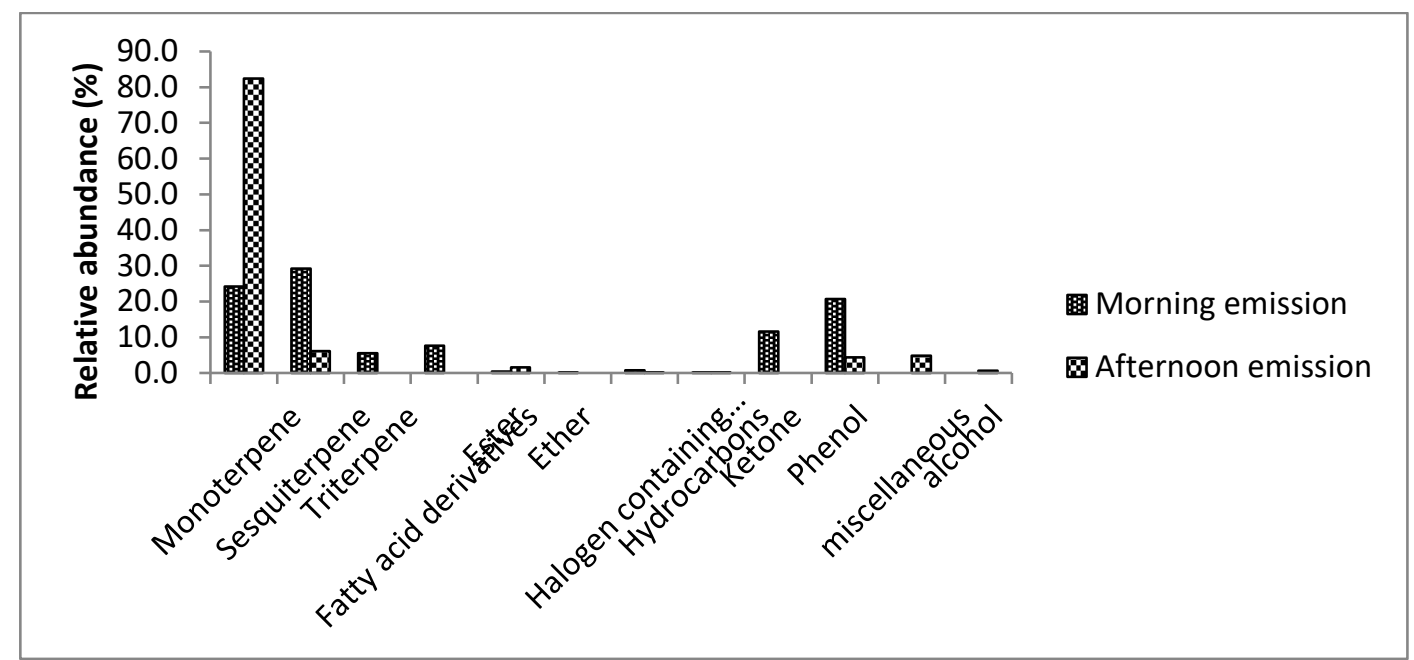

Fig 2. The volatile content comparison in different floral developmental stages. Aromatic compounds mainly include terpenoids (monoterpene, sesquiterpene and triterpene), alcohols, esters, aldehydes, ketones and phenols.
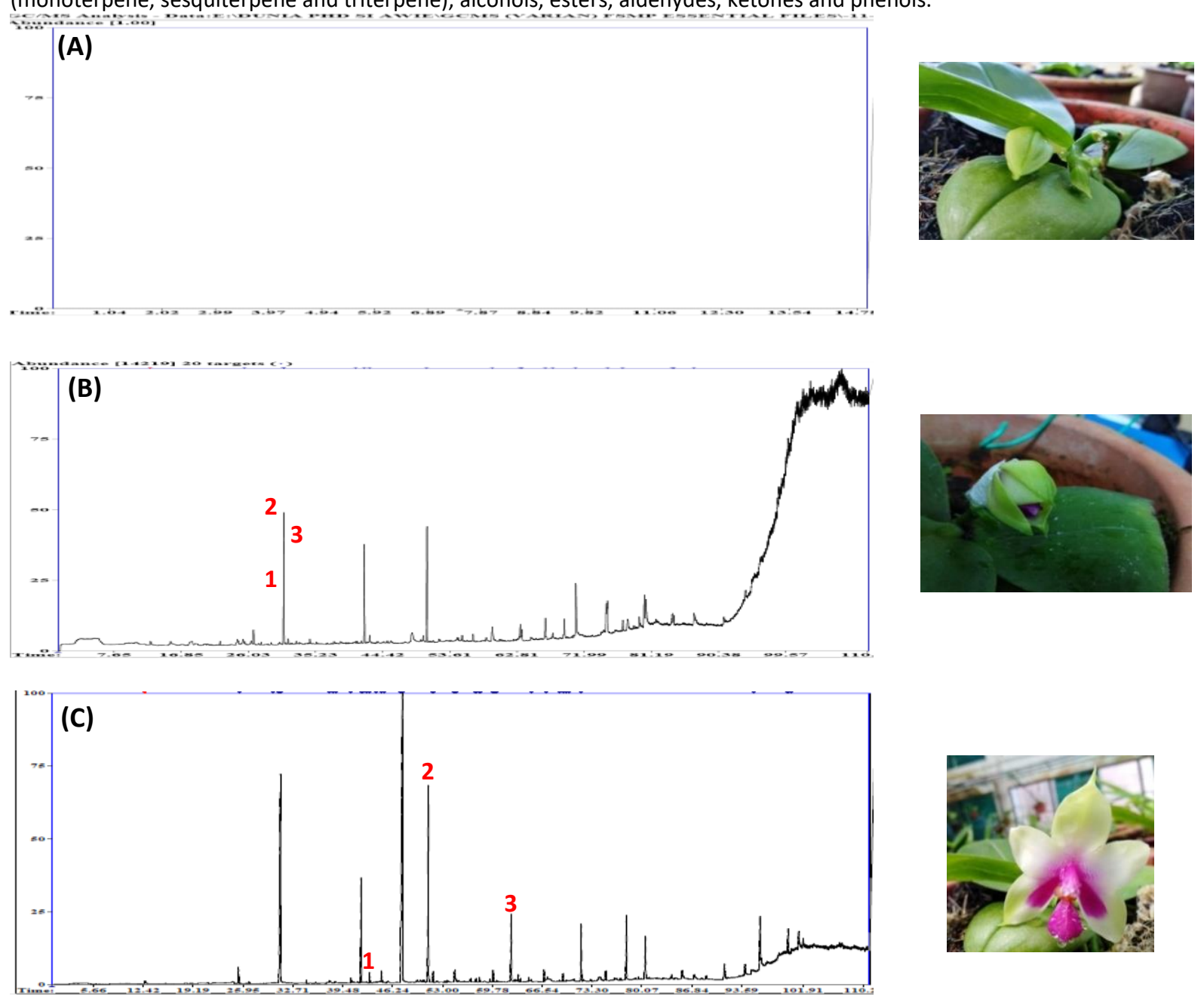

Fig 3. Comparison of chromatogram profile emission by Phalaenopsis bellina at three different floral developmental stages. (a) flower bud, (b) partial bloom, numbers on the graph represent the following compound (1) linalool, (2) linalyl anthranilate and (3) 17-octadecan-14-yn-1-ol and (c) full bloom, numbers on the graph represent the following compound (1) $\alpha$-farnesene, (2) 2,6bis(1,1-dimethylethyl)-1-(1-oxopropyl)phenol and (3) 5-isopropyl-2,4-imidazolidinedione 


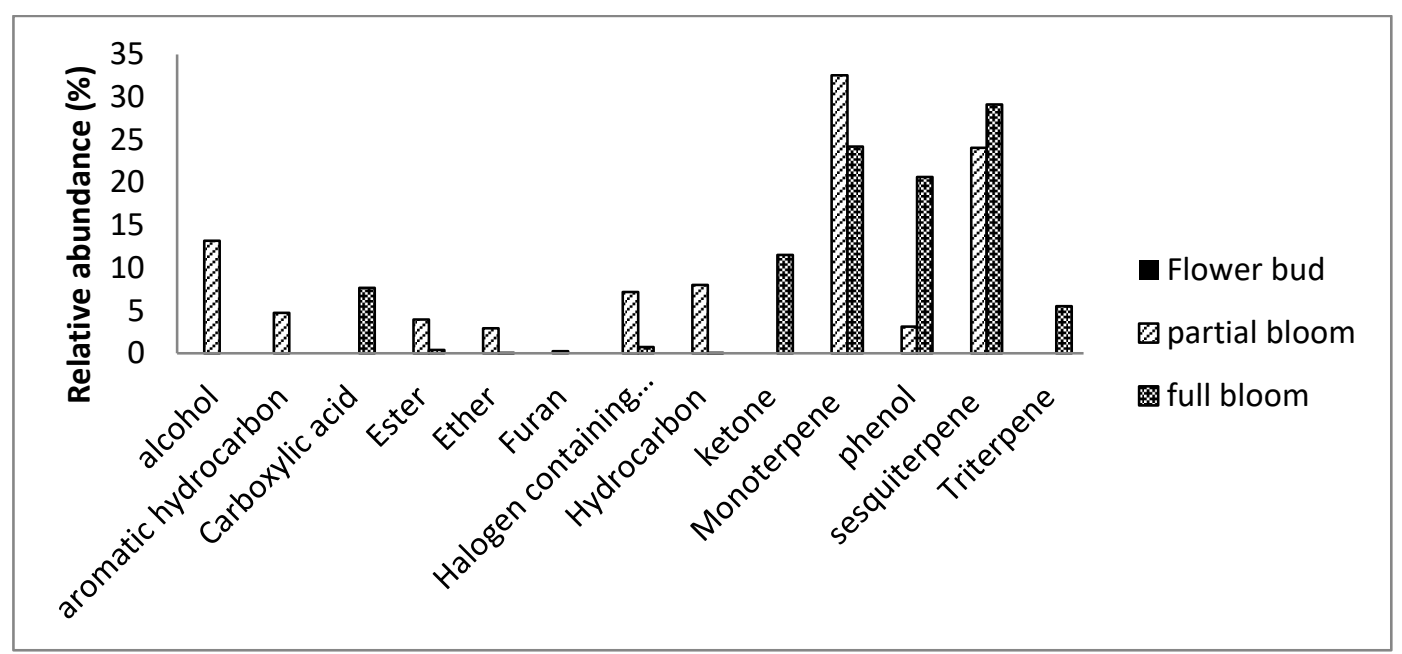

Fig 4. The volatile content comparison in different floral developmental stages. Aromatic compounds mainly include terpenoids (monoterpene, sesquiterpene and triterpene), alcohols, esters, aldehydes, ketones and phenols.

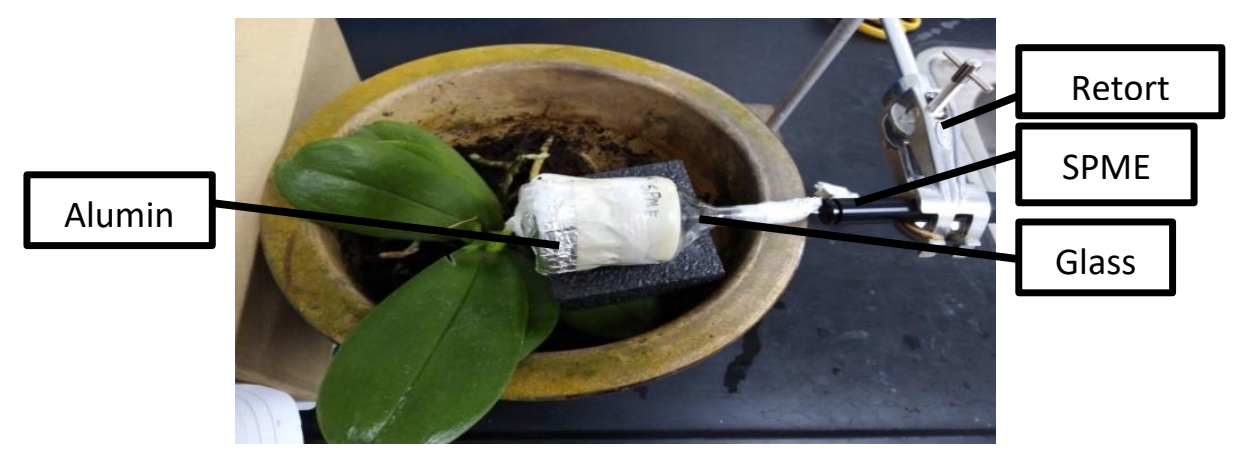

Fig 5. Solid Phase Micro Extraction (SPME) setting to trap the floral volatile emitted by P. bellina.

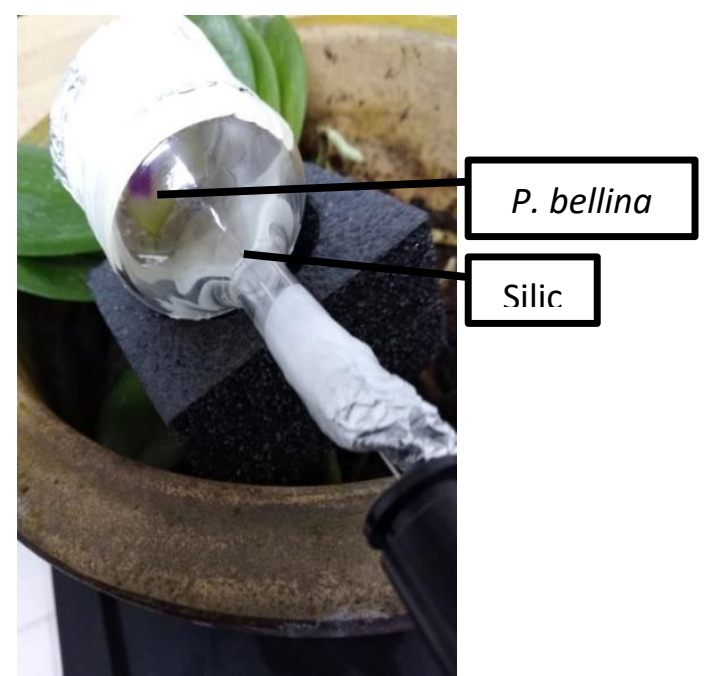

Fig 6. Close up figure of Solid Phase Micro Extraction (SPME) setting to trap the floral volatile emitted by P. bellina.

bud of $P$. bellina. Progressing into full bloom, total monoterpene was reduced to $24.23 \%$, while sesquiterpene emission was raised to $29.16 \%$. Triterpenes were also released during full bloom, with an abundance of $5.51 \%$. Partial bloom of $P$. bellina revealed emission of linalool as the highest abundance (32.09\%), followed by linalyl anthranilate (24.01\%) and 17-octadecan-14-in-1-ol (12.75\%). However, linalool emission was decreased drastically into $0.42 \%$, as well as linalyl anthranilate $(5.59 \%)$ moving into full bloom. In full bloom, $\alpha$-farnesene becomes the highest abundant compound (19.56\%). By looking into the emission of compound classes of $P$. bellina, the flower starts to emit its volatiles during partial bloom stage, in which terpenoid abundance was the highest $(56.6 \%)$ and increases to $58.9 \%$ during full bloom (Figure 4). Other volatile fractions that were detected during partial bloom were alcohols, hydrocarbons, esters, ethers, furans, halogen-containing groups and phenols. Additional volatile fractions, which were carboxylic acids, ketones and terpenoid triterpenes, were identified during full bloom. The results shown were comparable to a similar study conducted by Li et al. (2017) for volatile emission from Luculia yunannensis. The highest compound diversity was observed during full bloom (37 volatile compounds) compared to partial bloom (31 volatile 
compounds), with monoterpenes 3-carane and sesquiterpene $\alpha$-copaene being the dominant compounds emitted during the blooming period.

According to Steenhuisen et al. (2010), scent production was limited to certain flowering times and stages such as anthesis and receptivity also limit the unnecessary use of resources into producing scent after pollination. This might explains the emission profile of partial bloom of $P$. bellina in which a low number of volatile compounds were detected. Meanwhile, plants can also rapidly alter their volatile floral production in response to volatile floral cues from their flowering neighbours (Caruso \& Parachnowitsch, 2016; Ninkovic et al., 2016). This mechanism can increase the pollination rate and mating by increasing floral volatile emission to attract more pollinators (Li et al. 2017).

\section{Materials and methods}

\section{Plant materials}

Phalaenopsis bellina is an ornamental orchid with a sweet scent, which was purchased from local vendors in Malaysia. Volatile components were identified during the flowering period, cultivated in the Institute for Tropical and Biology Conservation greenhouse, controlled at $25 \pm 3^{\circ} \mathrm{C}$. A sampling of volatiles from $P$. bellina was performed during the morning (9.00 am $-9.30 \mathrm{am})$ and afternoon (3.00 pm - 3.30 pm). Sampling was also done in different floral developmental stages, which were on floral bud, partial bloom, and full bloom stages.

\section{Solid Phase Microextraction (SPME)}

Volatiles emitted by a single flower was absorbed by Solid Phase Micro-Extraction (SPME)(Supelco, USA), according to (Mohd-Hairul et al. 2010) for volatile study from Vanda Mimi Palmer, with slight modifications on incubation period. The SPME with silica fiber that was coated with $100 \mu \mathrm{m}$ polydimethylsiloxane (PDMS) was used to absorb the volatiles emitted by $P$. bellina flower. A single flower was put into a modified funnel without detaching the flower from the flower stalk (Figure 5 and 6). The back of the funnel was covered with aluminum foil to ensure no volatiles were escaped during trapping. The SPME holder was pressed to allow the silica fiber in the SPME to emerge from the SPME syringe and captured the volatiles produced by the flower for 30 minutes at ambient room temperature $\left(25 \pm 2^{\circ} \mathrm{C}\right)$.

\section{Gas Chromatography-Mass Spectrometry Analysis of Volatiles}

The SPME fiber that has trapped the volatiles was thermally desorbed for 3 minutes at $250^{\circ} \mathrm{C}$ in an injector Port of Varian GC-MS (Varian 450GC) equipped with Agilent J \& WVFWaxms Capillary column $(30 \mathrm{~m} \times 0.25 \mathrm{~mm} \times 0.25 \mu \mathrm{m})$. The oven temperature was: from $40^{\circ} \mathrm{C}$, hold 4 minutes, and then temperature ramp was set to $5^{\circ} \mathrm{C} / \mathrm{min}$ until it reaches $250^{\circ} \mathrm{C}$, where it is held for 10 minutes. The injections were performed in splitless mode, while the carrier gas used was helium at a constant flow of $1 \mathrm{~mL} / \mathrm{min}$. The transfer line to the mass spectrometer was maintained at $230^{\circ} \mathrm{C}$, and the ion source temperature was set at $250^{\circ} \mathrm{C}$. The mass spectra were obtained by using a mass selective detector with the electronic impact at $70 \mathrm{eV}$, in which the $\mathrm{m} / \mathrm{z}$ range was from 30-500. Compounds were identified by comparison with the National Institute of Standards and Technology 2008 (NIST
08). Volatile compound measurements were carried out by peak area normalization (expressed in percentage).

\section{Conclusion}

The floral scent is an essential component of the trait repertoire that increases the value of orchids in the horticulture industry. However, scent traits of Phalaenopsis bellina have received limited attention. This study revealed differences in the volatile profile in $P$. bellina flower in morning and afternoon emission, indicating timing influence and flowering stages on the volatile emission. Therefore, future work may focus on elucidating the molecular mechanisms of fragrance-related genes related to the terpenoid biosynthetic pathway.

\section{Acknowledgments}

This study was conducted with support from the Fundamental Research Grant Scheme (FRG0466-2017) from the Ministry of High Education (MOHE), Malaysia and UMSGREAT Research Grant (GUG0280-2/2018) from Universiti Malaysia Sabah. The authors also express gratitude to all who are directly and indirectly involved in this study.

\section{References}

B. Martin A (2005) The Vocabulary of Orchids: An Amateur Perspective. Australia

Banks DP (2003) Handy Pocket Guide to Orchids. Periplus Editions (HK) Ltd., Singapore

Beaman TB, Wood JJ, Beaman RS, Beaman JH (2001) Orchids of Sarawak. Natural History Publications (Borneo) Sdn. Bhd., Kota Kinabalu, Sabah, Malaysia

Bera P, Mukherjee C, Mitra A (2017) Enzymatic production and emission of floral scent volatiles in Jasminum sambac. Plant Sci 256:25-38.

Cardoso-Gustavson P, de Souza SR, de Barros F (2017) Floral volatile profile in Pleurothallidinae, an orchid subtribe pollinated by flies: ecological and phylogenetic considerations. Phytochem Lett 22:49-55.

Caruso CM, Parachnowitsch AL (2016) Do Plants Eavesdrop on Floral Scent Signals? Trends Plant Sci 21:9-15.

Chiu YT, Chen HC, Chang C (2017) The variation of oncidium rosy sunset flower volatiles with daily rhythm, flowering period, and flower parts. Molecules 22:.

Christenson EA, Whitten MW (1995) Phalaenopsis bellina (Rchb.f.) Christenson, a Segregate from P. Violacea Witte (Orchidaceae: Aeridinae). Brittonia 47:57-60.

Chuang Y-C, Hung Y-C, Tsai W-C, et al (2018) PbbHLH4 regulates floral monoterpene biosynthesis in Phalaenopsis orchids. J Exp Bot 69:4363-4377.

Chuang Y-C, Lee M-C, Chang Y-L, et al (2017) Diurnal regulation of the floral scent emission by light and circadian rhythm in the Phalaenopsis orchids. Bot Stud 58:50.

Fan Z, Li J, Li X, Yin H (2019) Composition analysis of floral scent within genus Camellia uncovers substantial interspecific variations. Sci Hortic (Amsterdam) 250:207213.

Hetherington-Rauth MC, Ramírez SR (2016) Evolution and diversity of floral scent chemistry in the euglossine beepollinated orchid genus Gongora. Ann Bot 118:135-148.

Hsiao Y-Y, Tsai W-C, Kuoh C-S, et al (2006a) Comparison of transcripts in Phalaenopsis bellina and Phalaenopsis 
equestris(Orchidaceae) flowers to deduce monoterpene biosynthesis pathway. BMC Plant Biol 6:14.

Hsiao YY, Tsai WC, Kuoh CS, et al (2006b) Comparison of transcripts in Phalaenopsis bellina and Phalaenopsis equestris (Orchidaceae) flowers to deduce monoterpene biosynthesis pathway. BMC Plant Biol 6:1-14.

Li Y, Wan Y, Sun Z, et al (2017) Floral scent chemistry of luculia yunnanensis (rubiaceae), a species endemic to China with sweetly fragrant flowers. Molecules 22:1-11.

Mahmood M, Chew YF (2008) Agrobacterium-mediated Genetic Transformation of Phalaenopsis bellina Using GFP and GUS Reporter Genes. Pertanika J Sci Technol 16:129139

Manzo A, Panseri S, Vagge I, Giorgi A (2014) Volatile fingerprint of italian populations of orchids using solid phase microextraction and gas chromatography coupled with mass spectrometry. Molecules 19:7913-7936.

Milet-Pinheiro P, Gerlach G (2017) Biology of the Neotropical orchid genus Catasetum: A historical review on floral scent chemistry and pollinators. Perspect Plant Ecol Evol Syst 27:23-34.

Mohd-Hairul AR, Namasivayam P, Cheng Lian GE, Abdullah JO (2010) Terpenoid, Benzenoid, and Phenylpropanoid Compounds in the Floral Scent of Vanda Mimi Palmer. J Plant Biol 53:358-366.
Ninkovic V, Markovic D, Dahlin I (2016) Decoding neighbour volatiles in preparation for future competition and implications for tritrophic interactions. Perspect Plant Ecol Evol Syst 23:11-17.

Phillips RD, Dixon KW, Peakall R (2012) Low population genetic differentiation in the Orchidaceae: implications for the diversification of the family. Mol Ecol 21:5208-5220.

Reis MG, Pansarim ER, Silva UF, et al (2004) Pollinator attraction devices ( floral fragrances ) of some Brazilian orchids. 2004:89-97

Shi T, Yue Y, Shi M, et al (2019) Exploration of Floral Volatile Organic Compounds in Six Typical Lycoris taxa by GC-MS. Plants 8:422.

Steenhuisen SL, Raguso RA, Jürgens A, Johnson SD (2010) Variation in scent emission among floral parts and inflorescence developmental stages in beetle-pollinated Protea species (Proteaceae). South African J Bot 76:779787.

Yeh CH, Tsai WY, Chiang HM, et al (2014) Headspace solidphase microextraction analysis of volatile components in Phalaenopsis Nobby's Pacific Sunset. Molecules 19:1408014093. 